\title{
Examiners' and Candidates' Perspectives on the First Performance-Based Assessment of the Saudi National Anesthesiology Board Final Exam
}

\author{
Abdulaziz M. Boker, MBBS, FRCPC, Med \\ Department of Anesthesia \& Critical Care, Director, Clinical Skill and Simulation Center \\ Faculty of Medicine, King Abdulaziz University, Jeddah, Saudi Arabia
}

\section{Correspondence}

Dr. Abdulaziz M. Boker

P.B. Box 80215, Jeddah 21589, Saudi Arabia

e.M: boker@hotmail.com

Submission: 16 Dec. 2016

Accepted: 28 Dec. 2016

\section{Citation}

Boker AM. Examiners' and candidates' perspectives on the first performancebased assessment of the Saudi National Anesthesiology Board final exam. JKAU Med Sci 2017; 24 (1): 11-21. DOI: 10.4197/Med. 24.1.2

\begin{abstract}
The Saudi Board of Anesthesia introduced a performance-based, objective, structured, clinical examination to supplement key and missing components in the traditional final board exam. This study aims to describe briefly the development, implementation and evaluation of the first high stake Saudi Board of Anesthesia exam after incorporation of objective, structured, clinical examination according to the participants' perspectives. After implementation of performance-based exams for the first time, a questionnaire was distributed tothecandidates and examiners to explore their perception of the exam. Twenty-three candidates and 20 examiners participated in the Saudi Board exam for anesthesia residency held on November 2015. The candidates as well as the examiners were very satisfied with the explanation of the exam process before the exam taking, the time allotted for the active stations as well as the organization and fairness of the exam with no significant difference between males and females. In conclusion, the objective, structured, clinical examination is well perceived by the examinees as a fair and acceptable assessment tool in the final exam of the Saudi Board of Anesthesia. We conclude that objective, structured, clinical examination is recommended to be used by other Saudi high stake exams.
\end{abstract}

\section{Keywords}

OSCE; Anesthesia; Board exam; Examiners; Candidates;

Perception

\section{Introduction}

$T$ he main goal of postgraduate health programs is graduation of competent practitioners. The components of the assessment plan of such programs should involve assessment of the candidates' ability to perform effectively in the domains associated with their own chosen specialty. In the end, residents are expected to be capable of effectively using their knowledge in the clinical settings with actual patients or in other words "doing" as per Millar classification. The challenge is to reliably and accurately assess this level of competency ${ }^{[1,2]}$. 
The Objective Structured Clinical Examination (OSCE) is used to teach as well as evaluate the clinical competence and high-stake decision regarding licensing of physicians $s^{[3,4]}$. Norcini and colleagues $^{[5]}$ outlined the criteria for good assessment that include: validity, reliability, equivalence, feasibility, educational effect, catalytic effect, and acceptability. On the other hand, the challenge is to develop an assessment tool that includes all the above criteria. Existing experience denotes that OSCE was categorized under the first group that fit with these criteria. Adding to its objectivity and reliability, OSCE helps to give feedback to the students on their performance as well as assessing the effectiveness of teaching and adequacy of content ${ }^{[6]}$.

The anesthesiology milestones outline five developmental levels, in each level the additional knowledge, skill, or behavior required for a physician at that stage is described. OSCE received great interest as an assessment tool of the six core competencies proposed by the Accreditation Council for Graduate Medical Education after the development of the anesthesiology residents' milestones ${ }^{[2]}$. The use of OSCE in anesthesiology training or certification was documented in a few reports. It was reported that "anesthesiology OSCE has been used for assessing physical examination skills, clinical and history-taking skills, airway management, resuscitation, blood product transfusion, anatomy, as well as statistics ${ }^{\prime \prime[7-9]}$.

Anesthesia Saudi Board final exam is one of the high-stake exams in Saudi Arabia. This classical exam includes written and oral exams. Written exams include multiple choice questions that cover knowledge relevant to specialty training while oral exams assess the ability of the candidate to respond to various scenarios and oral questions. At best, these two assessment tools cover the first two levels one of Miller's pyramid; "know" and "know how" [1]. Although the oral exam can demonstrate candidates' ability to verbally communicate during responding to the oral exam question, none of these methods can effectively assess neither "show how" nor "do" levels regarding psychomotor skills that are considered a must for assessment of clinical competence. The Saudi Board of Anesthesia aimed to introduce a performance-based OSCE to compensate for the missing component in the traditional final board exam. Therefore, this work aims to describe methods of development, implementation and assessment of the first national comprehensive final board exam after incorporation of OSCE.

\section{Subjects and Methods}

This study was approved by the Biomedical Ethics Research Committee at the Faculty of Medicine, King Abdulaziz University, Jeddah, Saudi Arabia.

\section{Exam Settings}

A national exam organizer committee was formed to design, prepare and supervise the implementation of the newly introduced performance-based assessment method; OSCE in the exam of Saudi Board of Anesthesia.

The committee decided that the total exam time to be $112 \mathrm{~min}$ per each candidate. The exam included 16 inactive stations ( 3 minutes each) and 8 active stations (8 minutes each). The inactive stations included Power Point Presentation-based or printed slides while the active stations included manikin or standardized patient-based stations. High fidelity simulation was used.

On the exam day, all teams in rooms with similar questions met for 10 minutes to review and agree on the key points about the case scenarios and most important features in each case.

\section{Blueprint Preparation}

The key limitation of assessment of clinical competence is its specificity. In other words, the ability to perform a given task does not guarantee the ability to perform other different tasks. Therefore, the importance of comprehensive sampling and efficient blueprinting of assessment technique was highlighted to assure validity and comprehensiveness of assessment technique. The exam organizer committee listed the number of cases included in the OSCE (Fig. 1). They prepared the blueprint to ensure content validity of the exam. The original as well as the sample OSCE blueprints are seen in Appendices 1 and 2.

\section{Examinee Preparation}

All candidates received written full description of various exam components 6 weeks before the exam. On the exam day, all candidates were briefed again on the procedures and proceedings of the exam before 


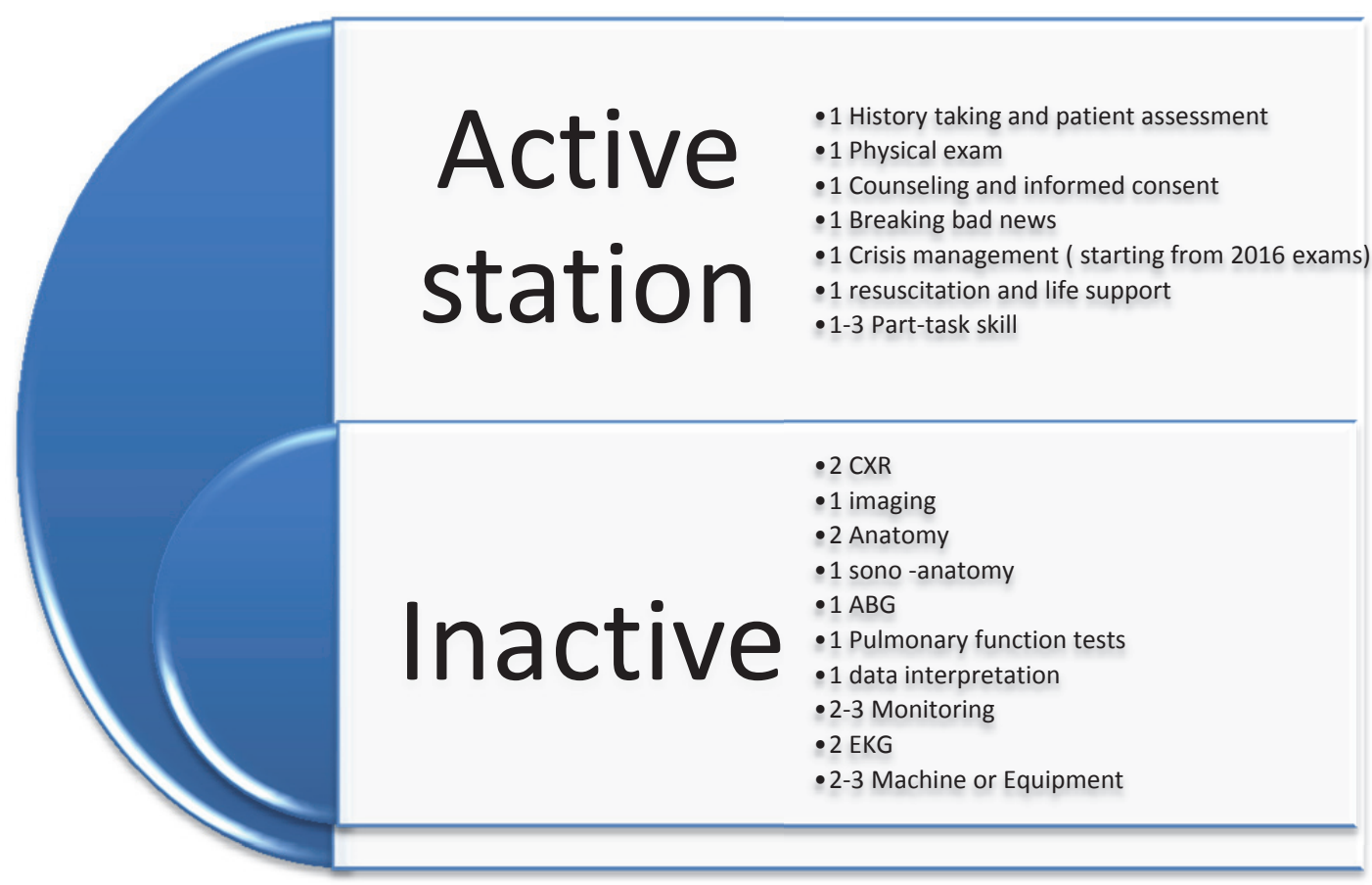

Figure 1. OSCE blueprint (XR: X-ray; ABG: Arterial blood gases; EKG: Electrocardiogram).

taking the exam. They were asked for any questions and all their queries were answered.

\section{Examiners Preparation}

All examiners were selected with previous experience in examinations. Full description as well as information about the exam were provided to the examiners and were discussed with them in scheduled meetings. Videos for training on filling the scoring sheets were provided in order to familiarize the examiners with the newly used system before the examination day. All potential examiners were given a chance to attend four exam preparation workshops over a two-year period. Feedback on individual examiners performances with suggestions to improve their examination skills were also provided.

\section{Scoring System}

The total marks of the inactive station are 80 marks. The candidate is considered successful "pass" if his/ her marks are more than the exam mean - 0.5 standard deviation (SD). The marks of the borderline candidate fall between (exam mean - 0.5 SD and exam mean - 1.5 $\mathrm{SD}$ ). Candidate with total marks less than (mean - 1.5 $\mathrm{SD}$ ) requires critical review. Example; if the exam mean is 60 and the SD is 10, the pass marks is 55 or more, the borderline marks between 45 to 54 and candidate with marks less than 45 needs critical review.

The criteria to pass the active stations included: having an average mark above $70 \%$; passing $60 \%$ of stations; and having no more than $30 \%$ of stations with a zero score. These 3 criteria should be achieved in order to pass while the candidate is considered borderline if achieving only two and will be considered fail if he/she achieves only one criteria.

To pass OSCE the candidate has to pass each of these two components.

\section{Obtaining Feedback and Assessing the Perception}

A questionnaire was constructed by the exam organizer committee to explore the perception of both examiners and candidates about the OSCE. It was distributed to all candidates and examiners at the end of the exam and they were requested to express their perception using a Likert scale of 7 points ranging from strongly disagree (0) to strongly agree (7). An open-end question asking about the suggestions for improvement of the OSCE in the next exam was included. All the examiners and candidates filled the questionnaire with $100 \%$ response rate. 
Examiners' and Candidates' Perspectives on the First Performance-Based Assessment of the Saudi National Anesthesiology... A.M. Boker

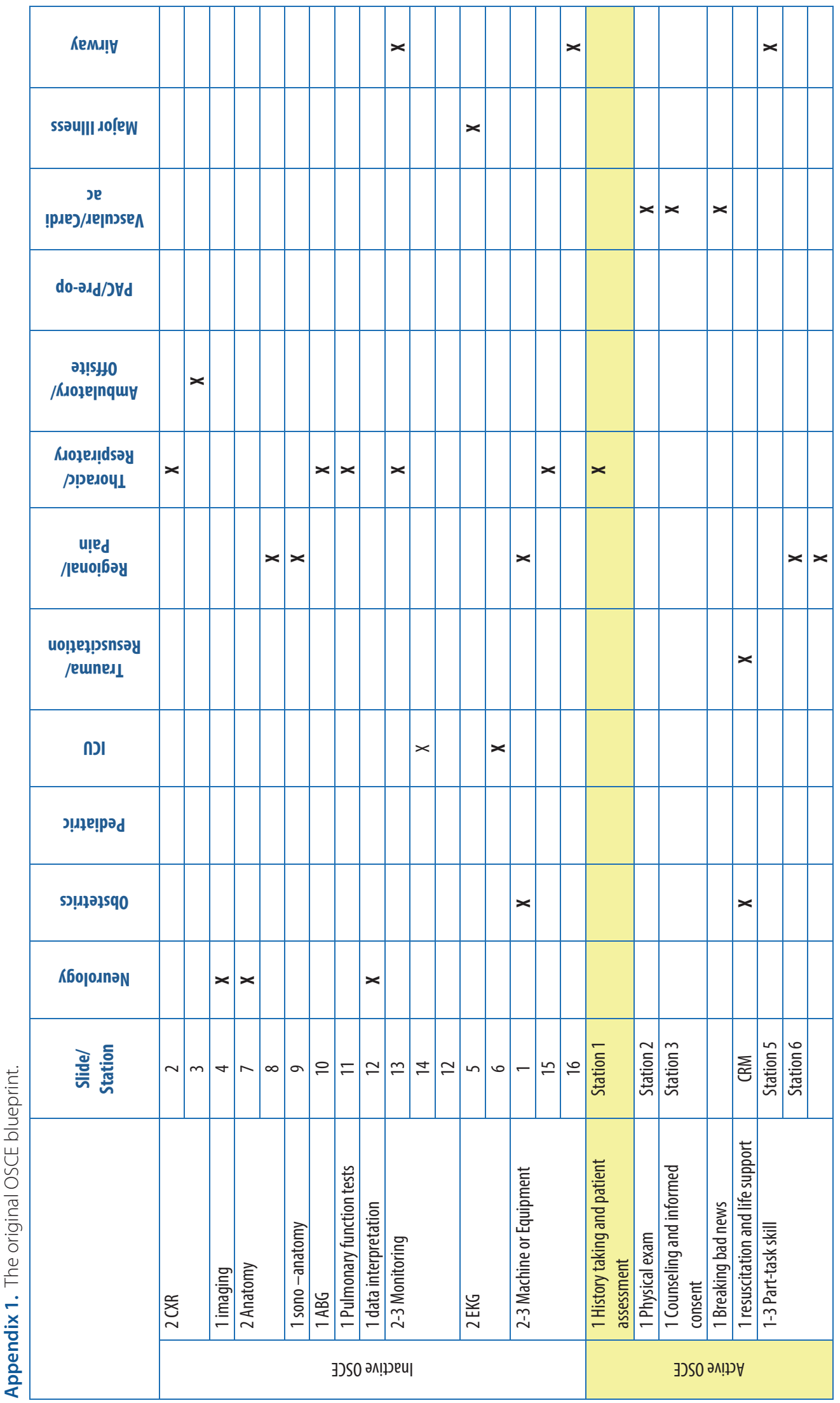




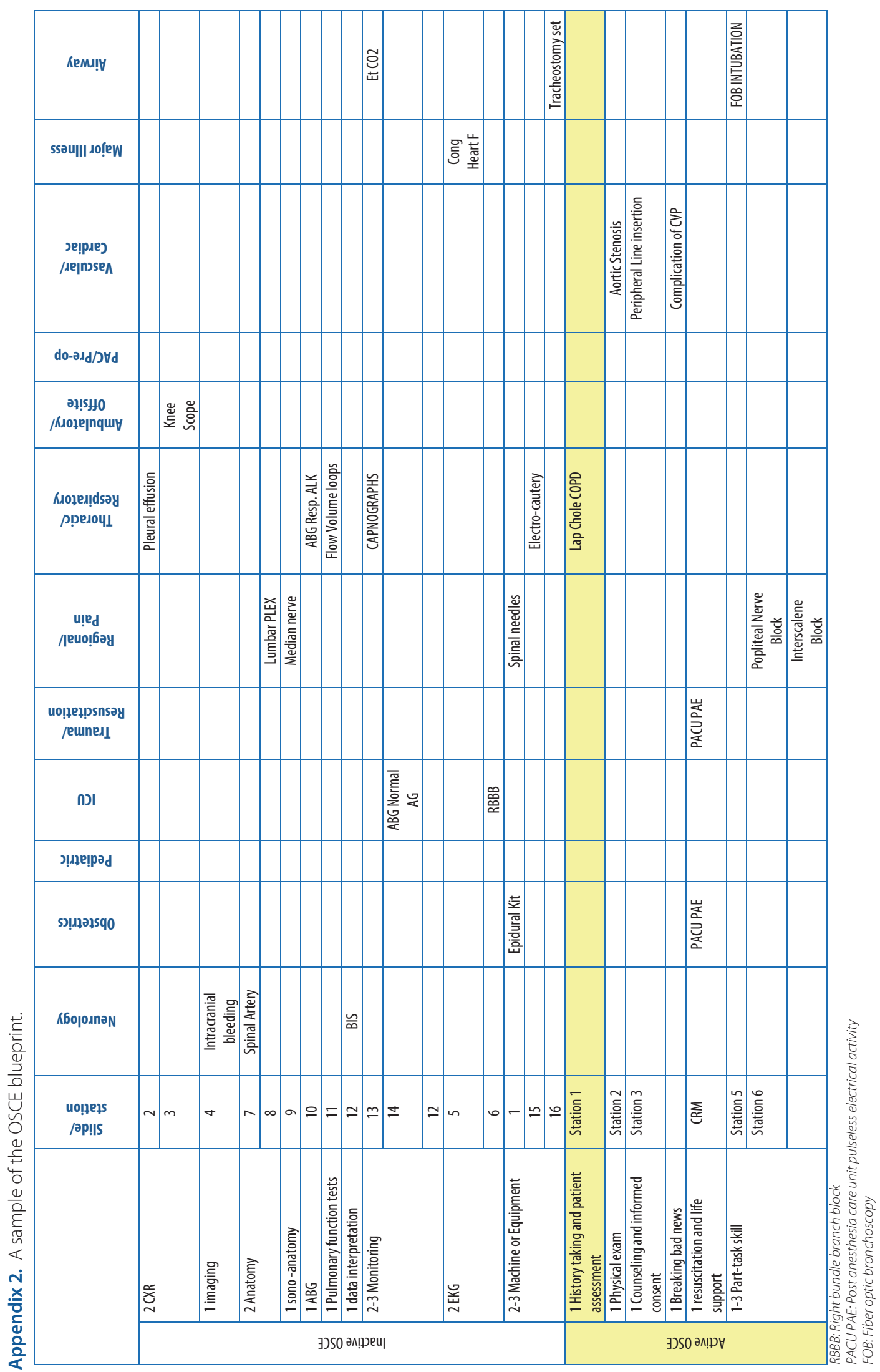


Data was collected and analyzed using the statistical package of social science (SPSS) program version 16 Inc. The normal distribution of the data was assessed using the Kolmogrov-Smirnov test. The quantitative data was expressed as mean and standard deviation (SD) or as number and percentage. The Student t-test was used to test significance for quantitative data of two groups. Kendal correlation was used to study the correlation between level of difficulty as ordinal variables and the perception of candidates as quantitative variables. $P$ value $<0.05$ is considered significant.

\section{Results}

Twenty-three candidates participated in the Saudi Board exam for anesthesia residency that was held on November 2015 (12 female and 11 male residents). Twenty examiners participated in this exam and most of them were male (19 male versus 1 female examiner) (Table 1). All the examiners considered the OSCE to be of moderate difficulty versus about $30 \%$ of the examinees. On the other hand, about $60 \%$ of the examinees considered the OSCE of low difficulty (Table 1).

The candidates were very satisfied with the explanation of the exam process prior to the exam taking, the time allotted for the active stations as well as the organization and fairness of the exam with no significant difference between male and female. It was observed that females were significantly $(p=0.02)$ more satisfied than the males regarding the time allotted to the inactive stations and considered it adequate. Male candidates preferred the OSCE more than the oral exam and the difference between males and females was of statistical significance $(p=0.04)$ (Table 2$)$.

Candidates' perception of OSCE according to the perceived level of difficulty was also compared.
The candidates who perceived the OSCE exam with moderate or high difficulty were significantly less satisfied with the exam regarding the importance of learning objectives reflected by the inactive station $(p=0.001)$, the balance between clinical and inactive stations $(p=0.02)$ and the adequacy of the time allotted to clinical stations $(p=0.03$ ) (Table 3 ). In addition, there was significant negative correlation between the perceived level of OSCE difficulty and the perceived importance of the learning objectives of the subjects reflected by the inactive stations $(p<0.001)$ as well as the balance between the clinical and inactive stations $(p<0.001)$ (Table 4).

A comparison between the examiners and candidates' perception of OSCE was done. It showed that the examiners were significantly more satisfied than the candidates regarding the similarity of the material covered in clinical teaching sessions and OSCE clinical stations $(p=0.005)$, the clarity of station instructions $(p=0.04)$, explanation of the exam process before the exam $(p<0.001)$ as well as good organization $(p<0.001)$ and fairness of the exam $(p<0.001)$ (Table 5$)$.

When asked through an open-ended question about issues that could improve the exam for next year's residents, the candidates mentioned reintroduction of MOCK exams and allowing more time for the inactive stations. Other candidates suggested to explain the details of the exam to the candidates ahead of the exam, increase the number of the active sessions at the expense of the inactive ones and early release of blueprints of OSCE as well as the objectives of stations.

The examiners mentioned other issues that included; increasing the number of the training workshops conducted at different regions and being meticulous in preparing the exam room to match its checklist.

Table 1. Gender and perception of the difficulty of OSCE in the Saudi board exam for anesthesia residency in $2015^{*}$.

\begin{tabular}{|l|c|c|c|c|}
\hline \multicolumn{1}{|c|}{ Variables } & \multicolumn{2}{c|}{$\begin{array}{c}\text { Candidates } \\
(\mathbf{N}=23)\end{array}$} & \multicolumn{2}{c|}{$\begin{array}{c}\text { Examiners } \\
(\mathbf{N}=20)\end{array}$} \\
\hline & $\mathbf{N}$ & $\%$ & $\mathbf{N}$ & $\%$ \\
\hline $\begin{array}{l}\text { Gender } \\
\text { Male }\end{array}$ & 11 & $(47.83 \%)$ & 19 & $(95 \%)$ \\
Female & 12 & $(52.17 \%)$ & 1 & $(5 \%)$ \\
\hline $\begin{array}{l}\text { Overall exam difficulty } \\
\text { Low }\end{array}$ & 14 & $(60.87 \%)(30.43 \%)$ & 20 & $(100 \%)$ \\
Moderate & 7 & $(8.7 \%)$ & - & - \\
High & 2 & & - & - \\
\hline
\end{tabular}


Examiners' and Candidates' Perspectives on the First Performance-Based Assessment of the Saudi National Anesthesiology... A.M. Boker

Table 2. Candidates' perception of OSCE according to the gender*.

\begin{tabular}{|c|c|c|c|c|c|}
\hline & $\begin{array}{c}\text { Male } \\
\text { Mean } \pm \text { SD } \\
\mathrm{N}=11\end{array}$ & $\begin{array}{c}\text { Females } \\
\text { Mean } \pm \text { SD } \\
\mathrm{N}=12\end{array}$ & Total & t value & P value** \\
\hline The clinical stations were similar to material covered in clinical teaching sessions & $5.18 \pm 0.87$ & $4.66 \pm 1.66$ & $5.9 \pm 0.78$ & 0.91 & 0.37 \\
\hline The inactive stations reflected important learning objective of the subject & $4.09 \pm 1.81$ & $4.5 \pm 1.88$ & $4.35 \pm 2.79$ & 0.53 & 0.62 \\
\hline There was a good balance between clinical and inactive stations & $4.27 \pm 1.19$ & $4.25 \pm 1.54$ & $4.55 \pm 2.56$ & 0.04 & 0.96 \\
\hline The instructions in each station were very clear & $4.45 \pm 1.8$ & $5 \pm 1.95$ & $5.75 \pm 1.25$ & 0.68 & 0.50 \\
\hline The time allotted to clinical stations was adequate & $5.45 \pm 1.03$ & $5.25 \pm 1.28$ & $6.1 \pm 1.61$ & 0.42 & 0.68 \\
\hline The time allotted to inactive stations was adequate & $2.27 \pm 1.73$ & $4.33 \pm 1.55$ & $4.35 \pm 2.51$ & 2.33 & $0.02^{*}$ \\
\hline The exam process was well explained to me before & $4 \pm 2.14$ & $4 \pm 2.04$ & $6.3 \pm 0.97$ & 0 & 0.99 \\
\hline The exam was well organized & $5.09 \pm 1.3$ & $5.41 \pm 2.02$ & $6.55 \pm 0.79$ & 0.45 & 0.65 \\
\hline The exam format is fair & $3.81 \pm 1.72$ & $4.84 \pm 1.74$ & $6.3 \pm 0.73$ & 1.4 & 0.18 \\
\hline I prefer this format more than the oral exam & $4.94 \pm 2.07$ & $3.25 \pm 2.07$ & $5.3 \pm 1.34$ & 2.06 & $0.04^{*}$ \\
\hline
\end{tabular}

*Student's t test was used

** Significance was considered at $p$ value less than 0.05

Table 3. Candidates' perception of OSCE according to the perceived level of difficulty*

\begin{tabular}{|c|c|c|c|c|}
\hline & $\begin{array}{l}\text { Low Difficulty } \\
\text { Mean } \pm \text { SD } \\
N=14\end{array}$ & $\begin{array}{c}\text { Moderate and High Difficulty } \\
\text { Mean } \pm \text { SD } \\
\mathrm{N}=9\end{array}$ & t Value & P Value** \\
\hline The clinical stations were similar to material covered in clinical teaching sessions & $5.07 \pm 1.26$ & $4.66 \pm 1.5$ & 0.69 & 0.49 \\
\hline The inactive stations reflected important learning objective of the subject & $5.35 \pm 0.74$ & $2.66 \pm 1.80$ & 5.07 & $0.001^{* * *}$ \\
\hline There was a good balance between clinical and inactive stations & $4.78 \pm 1.12$ & $3.44 \pm 1.33$ & 2.6 & $0.017^{*}$ \\
\hline The instructions in each station were very clear & $4.42 \pm 2.1$ & $5.22 \pm 1.48$ & 1.06 & 0.301 \\
\hline The time allotted to clinical stations was adequate & $5.71 \pm 0.61$ & $4.77 \pm 1.56$ & 2.33 & $0.031^{*}$ \\
\hline The time allotted to inactive stations was adequate & $3.57 \pm 1.86$ & $3.55 \pm 1.80$ & 0.02 & 0.98 \\
\hline The exam process was well explained to me before & $3.92 \pm 2.16$ & $4.11 \pm 2.02$ & 0.335 & 0.74 \\
\hline The exam was well organized & $5.35 \pm 1.49$ & $5.11 \pm 2.02$ & 0.45 & 0.65 \\
\hline The exam format is fair & $4.57 \pm 1.86$ & 4. \pm 1.65 & 0.74 & 0.46 \\
\hline I prefer this format more than the oral exam & $4.35 \pm 2.06$ & $3.55 \pm 2.12$ & 0.89 & 0.37 \\
\hline
\end{tabular}

*Student's t test was used

** Significance was considered at $p$ value less than 0.05

Table 4. Correlation between candidates' perception of OSCE and their perceived level of difficulty*.

\begin{tabular}{|l|c|c|}
\hline \multicolumn{1}{|c|}{ Perception } & \multicolumn{2}{c|}{ Level of Difficulty } \\
\cline { 2 - 3 } & Correlation Coefficient & p value** \\
\hline The clinical stations were similar to material covered in clinical teaching sessions & -0.205 & 0.34 \\
\hline The inactive stations reflected important learning objective of the subject & -0.76 & $<0.001$ \\
\hline There was a good balance between clinical and inactive stations & -0.54 & 0.001 \\
\hline The instructions in each station were very clear & 0.140 & 0.52 \\
\hline The time allotted to clinical stations was adequate & -0.40 & 0.055 \\
\hline The time allotted to inactive stations was adequate & -.046 & 0.835 \\
\hline The exam process was well explained to me before & 0.134 & 0.54 \\
\hline The exam was well organized & 0.122 & 0.59 \\
\hline The exam format is fair & 0.035 & 0.875 \\
\hline I prefer this format more than the oral exam & -0.186 \\
\hline The clinical stations were similar to material covered in clinical teaching sessions & -0.180 & 0.39 \\
\hline
\end{tabular}

*Kendal correlation was used to study the correlation between level of difficulty as ordinal variables and the perception of candidates as quantitative variables.

${ }^{* *}$ Significance was considered at $p$ value less than 0.05 
Examiners' and Candidates' Perspectives on the First Performance-Based Assessment of the Saudi National Anesthesiology... A.M. Boker

Table 5. Comparison between faculty and candidate perception of OSCE*.

\begin{tabular}{|c|c|c|c|c|}
\hline & $\begin{array}{c}\text { Examiners } \\
\text { Mean } \pm \text { SD } \\
n=20\end{array}$ & $\begin{array}{c}\text { Candidates } \\
\text { Mean } \pm \text { SD } \\
n=23\end{array}$ & Student t Test & p value** \\
\hline The clinical stations were similar to material covered in clinical teaching sessions & 5.90 .78 & $4.91 \pm 1.34$ & 2.95 & 0.005 \\
\hline The inactive stations reflected important learning objective of the subject & $4.35 \pm 2.79$ & $4.3 \pm 1.81$ & 0.071 & 0.943 \\
\hline There was a good balance between clinical and inactive stations & $4.55 \pm 2.56$ & $4.26 \pm 1.35$ & 0.47 & 0.36 \\
\hline The instructions in each station were very clear & $5.75 \pm 1.25$ & $4.7 \pm 1.88$ & 2.15 & 0.036 \\
\hline The time allotted to clinical stations was adequate & $6.1 \pm 1.61$ & $5.34 \pm 1.13$ & 1.70 & 0.095 \\
\hline The time allotted to inactive stations was adequate & $4.35 \pm 2.51$ & $3.56 \pm 1.82$ & 1.20 & 0.623 \\
\hline The exam process was well explained before & $6.3 \pm 0.97$ & $4 \pm 2.04$ & 4.72 & $<0.001$ \\
\hline The exam was well organized & $6.55 \pm 0.79$ & $5.26 \pm 1.68$ & 5.21 & $<0.001$ \\
\hline The exam format is fair & $6.3 \pm 0.73$ & $4.34 \pm 1.73$ & 4.74 & $<0.001$ \\
\hline I prefer this format more than the oral exam & $5.3 \pm 1.34$ & $4.04 \pm 2.07$ & 2.37 & 0.022 \\
\hline
\end{tabular}

"Student's t test was used

** Significance was considered at $p$ value less than 0.05

\section{Discussion}

One of the most important things for the future anesthesiologist is to master the practical skills in anesthesia. In this specialty, assessment is crucial for student's learning strategies. Therefore, in order to achieve a desired outcome of an assessment, tools that yield valid, reliable and accurate results should be used ${ }^{[10]}$. It was reported that assessment in anesthesia should determine the knowledge, technical, practical, professional, interpersonal and communication skills ${ }^{[1,12]}$. Therefore, growing evidence exists on the appropriateness of simulation-based training and assessment of "show how" levels of competence in anesthesiology ${ }^{[13]}$.

Since the OSCE has been introduced by Harden et al. ${ }^{[14]}$, as a means to assessing clinical competency, it is being used increasingly for both undergraduate and postgraduate students. Much research was conducted on OSCE either worldwide or nationally in Saudi Arabia. Although there are many studies about the perceptions of the examinees regarding OSCE as an assessment tool and its educational impact on undergraduate students, [15-19] relatively fewer studies with similar objectives were conduct on the postgraduate students. Therefore, this study aims to assess the perception of anesthesia residents of the Saudi Board about OSCE in the Board exam. It was reported that "the content validity of the OSCE is well documented". Blueprinting and construction of solid framework are behind this level of validation ${ }^{[14,20]}$. Because of that, preparation of the blueprint to ensure content validity of the exam was among the crucial steps conducted by the national exam organizer committee of the Saudi Board of Anesthesia.
It was described that equality in the level of questioning that allows fair judgment when assessing medical students as well as unbiased scoring systems were stated as two important qualities in methods of assessment of clinical students' competency. Unfortunately, these two qualities are compromised in the traditional methods of assessment of clinical competency ${ }^{[21]}$.

OSCE focuses on "the standardization of scoring and structure of the exam". It minimizes the content specificity, and reduces rater and patient performance biases. One of the major aims of the OSCE is to restrict the variability in student marking to the student's factors rather than other factors that could lead to unreal judgment in the student's assessment ${ }^{[14]}$. Consistent with this evidence, the candidates in this study were very satisfied with the fairness of the OSCE with no significant difference between males and females. This finding was in line with that of the recent study conducted in India among the anesthesiology postgraduate students on the use of OSCE compared to the conventional examinations as formative assessment tools. The students perceived OSCE as a fair (54.2\%) and unbiased tool (37.1\%) with more standardized scoring $(25.7 \%)^{[13]}$.

In this study the candidates were also very satisfied with explanation of the exam process prior to the exam. This was done intentionally as a response to the previous recommendations of Hetaimish and Elbadawi ${ }^{[21]}$. They said that OSCE courses that aim to orient students with the exam process may decrease or nullify students' anxiety, and increase raters' awareness about the OSCE. Among the causes behind the candidates' satisfaction with the exam was the good organization of the OSCE. 
Examiners' and Candidates' Perspectives on the First Performance-Based Assessment of the Saudi National Anesthesiology...

Adding to that the good preparation and training of the faculty who participated as examiners in the OSCE through attending many preparatory workshops. The latter were described to be valuable opportunities for the organizational committee and the faculty to clarify any ambiguous areas and to generate constructive solutions ${ }^{[22]}$. The candidates in this study, specifically the males, perceived the OSCE as a preferable format of assessment than the routine oral exam. In many other studies, the conventional method of assessing practical skills is not accepted by students as the irrelevance and inconsistency of the examiner questions may lead to inconsistency in scores ${ }^{[23]}$.

In general, the acceptability of examinee to OSCE was reported. ${ }^{[24]}$ On speaking to the anesthesiology post graduate students, specifically, they showed a positive perception towards OSCE. They perceived it as structured $(25.7 \%)$, less stressful $(82.5 \%)$ and easier to pass than conventional methods of assessment ${ }^{[13]}$.

Limitations of the study and further recommendations: The small sample size in this study is one of the limitations. Although the candidates of the Saudi Board Exam for anesthesia in 2015 included in this study were from various health colleges, a further longitudinal study including examinee candidates in consecutive years is recommended in order to support the generalizability of the results.

It can be concluded, from the results of this study, that well designed OSCE is well perceived by the examinees as a fair, structured and acceptable assessment tool in the final exam of the Saudi Board of Anesthesia. Therefore, it is recommended to be used by other Saudi Board exams as it is considered a significantly better evaluation tool than conventional methods in terms of objectivity and reliability.

\section{Conflict of Interest}

The author has no conflict of interest.

\section{Disclosure}

The author did not receive any type of commercial support either in forms of compensation or financial for this study. The author has no financial interest in any of the products or devices, or drugs mentioned in this article.

\section{Ethical Approval}

Obtained.

\section{Acknowledgements}

The authors would like to acknowledge the Anesthesia and Critical Care Boards for their support.

\section{References}

[1] Miller GE. The assessment of clinical skills/competence/ performance. Acad Med 1990; 65(9): S63-67

[2] Hastie MJ, Spellman JL, Pagano PP, Hastie J, Egan BJ. Designing and implementing the objective structured clinical examination in anesthesiology. Anesthesiol 2014; 120(1): 196-203.

[3] Epstein R. Assessment in medical education. N Engl J Med 2007; 356: 387-396.

[4] Turner JL, Danoski ME. Objective Structured Clinical Exams: a critical review. Fam Med 2008; 40(8): 574-578.

[5] Norcini J, Anderson B, Bollela V, Burch V, Costa MJ, Duvivier R, Galbraith R, Hays R, Kent A, Perrott V, Roberts T. Criteria for good assessment: consensus statement and recommendations from the Ottawa 2010 Conference. Med Teach 2011; 33(3): 206-214.

[6] Wani P, Dalvi V. OSPE versus traditional clinical examination in human physiology: Student perception. Int J Med Sci Public Health 2013; 2(3): 543-547.

[7] Bromley LM. The Objective Structured Clinical ExamPractical aspects. Curr Opin Anaesthesiol 2000; 13(6): 675678.

[8] Corrie K, Wiles M, Flack J, Lamb J. A novel objective structured clinical examination for the assessment of transfusion practice in anesthesia. Clin Teach 2011; 8(2): 97-100.

[9] Berkenstadt H, Ben-Menachem E, Dach R, Ezri T, Ziv A, Rubin $\mathrm{O}$, Keidan I. Deficits in the provision of cardiopulmonary resuscitation during simulated obstetric crises: Results from the Israeli Board of Anesthesiologists. Anesth Analg 2012; 115(5): 1122-1126.

[10] Frntz JM, Rowe M, Hess DA, Rhoda AJ, Sauls BL, Wegner L. Student and staff perceptions and experiences of the introduction of objective structured practical examinations: A pilot study. Afr J Health Prof Educ 2013; 5(2): 72-74.

[11] Chan CY. Is OSCE valid for evaluation of the six ACGME general competencies? J Chin Med Assoc 2011; 74(5): 193194.

[12] Ben-Menachem E, Ezri T, Ziv A, Sidi A, Brill S, Berkenstadt $\mathrm{H}$. Objective structured clinical examination-based assessment of regional anesthesia skills: The Israeli National Board Examination in Anesthesiology experience. Anesth Analg 2011; 112(1): 242-245.

[13] Jindal P and Khurana G. The opinion of post graduate students on objective structured clinical examination in Anaesthesiology: A preliminary report. Indian J Anaesth 2016; 60(3): 168-173. 
[14] Harden RM, Stevenson M, Downie WW, Wilson GM. Assessment of clinical competence using objective structured examination. BMJ 1975; 13(1): 41-54.

[15] Shawky S. Experience with the objective structured examination as a tool for students' assessment in the Department of Community Medicine and Primary Health Care in a university [corrected] in Western Saudi Arabia. Saudi Med J 2002; 23(2): 151-155.

[16] Kalantan K, Pyrne N, Al-Faris E, Al-Taweel A, Al-Rowais N, Abdul Ghani H, Eldin Magzoub M. Students' perceptions towards a family medicine attachment experience. Educ Health (Abingdon) 2003; 16(3): 357-365.

[17] Bakhsh TM, Sibiany AM, Al-Mashat FM, Meccawy AA, AlThubaity FK Comparison of students' performance in the traditional oral clinical examination and the objective structured clinical examination. Saudi Med J 2009; 30(4): 555-557.

[18] Raheel H, Naeem N. Assessing the Objective Structured Clinical Examination: Saudi family medicine undergraduate medical students' perceptions of the tool. J Pak Med Assoc 2013; 63(10): 1281-1284.

[19] Al-Mohaimeed A, Midhet F, Barrimah I, Khan NZ, Sharaf FK, Alnohair S. Students' perceptions about the family medicine course in Qassim, Saudi Arabia. Med Teach 2014; 36 (1): S49-54

[20] Newble DI, Hoare J, Elmslie RG. The validity and reliability of a new examination of the clinical competence of medical students. Med Educ 1981; 15: 46-52.

[21] Hetaimish B and Elbadawi H. OSCE Assessment for Medical Student Clinical Skills and Performance, Are We Doing It The Right Way? Int J Sci Res 2015; 4(11): 936-967.

[22] Whelan GP. Educational Commission for Foreign Medical Graduates: clinical skills assessment prototype. Med Teach 1999; 21(2): 156-160.

[23] Kundu D, Das HN, Sen G, Osta M, Mandal T, Gautam D. Objective structured practical examination in biochemistry: An experience in medical college, Kolkata. J Nat Sci Biol Med 2013; 4(1): 103-107.

[24] Khan KZ, Ramachandran S, Gaunt K, Pushkar P.The Objective Structured Clinical Examination (OSCE): AMEE Guide No. 81. Part I: an historical and theoretical perspective. Medical Teacher 2013; 35(9): e1437-1446. 


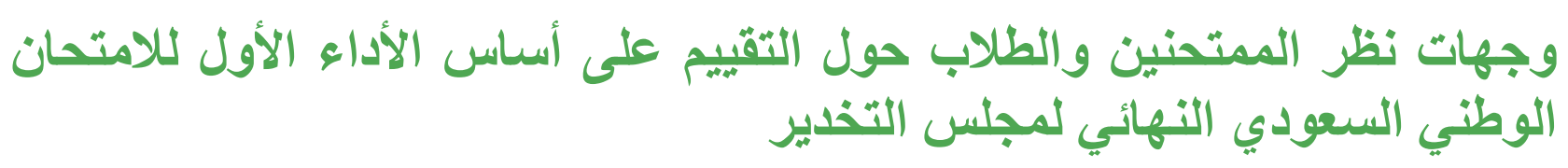

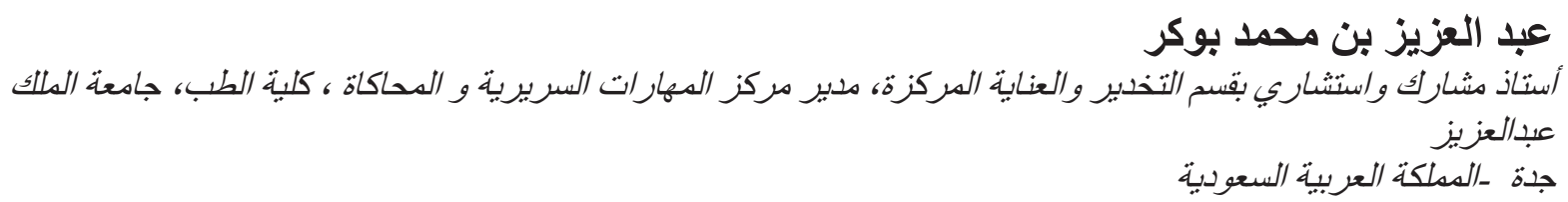

المستخلص. أدخل المجلس السعودي للتخدير الاختبار السريري المنظم الموضوعي القائم على تقييم الأداء من أجل استكمال

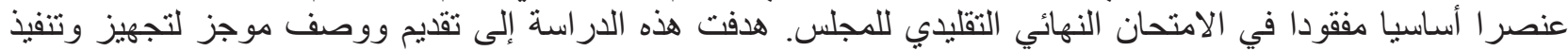

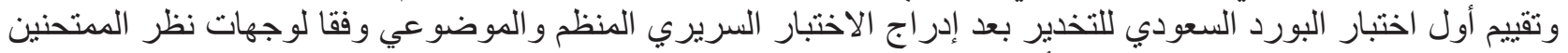

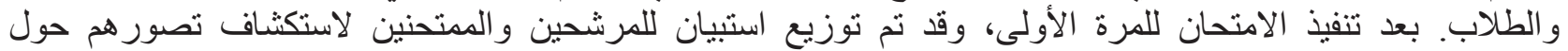

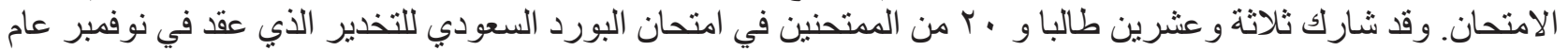

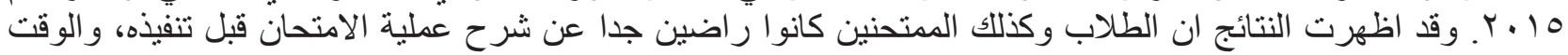

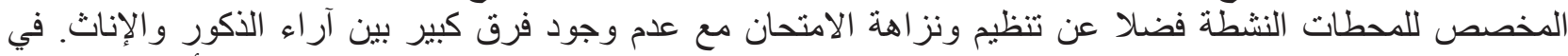

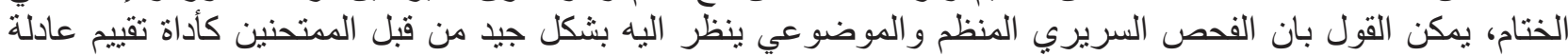

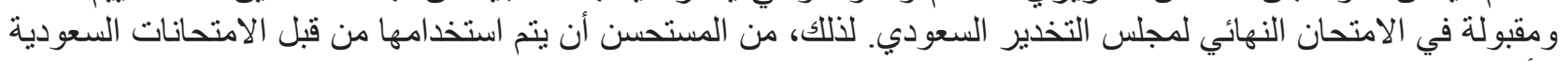
الأخرى ذات الاهية الاندئ الاعلى. 